\title{
14
}

\section{Concluding Remarks: Data Collection in FCV Environments}

\author{
Johannes Hoogeveen and Utz Pape
}

Environments characterized by fragility, conflict, and violence (FCV) are very heterogenous, comprising countries as different as Togo and Tuvalu, but also Syria or Chad. Despite this heterogeneity, there are major commonalities. All fragile countries are characterized by limited administrative capacities, country situations are volatile and uncertain, and there is a high degree of data deprivation. Many, but not all, fragile countries are affected by violence. When considering how to address urgent data gaps in fragile countries, the potential for data collectors to get exposed to violence is a defining feature.

In non-violent, fragile countries, efforts should be made to strengthen capacities by rebuilding and strengthening existing statistical systems. As capacities are limited, care should be taken not to overload strained systems with major reform efforts or overly ambitious statistics

\footnotetext{
J. Hoogeveen $(\bowtie) \cdot$ U. Pape

World Bank, Washington, DC, USA

e-mail: jhoogeveen@worldbank.org

U. Pape

e-mail: upape@worldbank.org 
production programs. Certain areas may have to be prioritized, such as the creation of up-to-date sampling frames, as high volatility-often observed in pre- or post-crisis countries-outdates existing sampling frames more rapidly than in a normal context. Given the cost and logistics to update sampling frames with traditional methods, Chapters 7 and 8 offer alternative approaches that could be followed to bridge the gap until a traditional population or enterprise census can take place.

As non-violent, fragile countries are prone to volatility, strengthening the capacity to collect data during times of crisis is recommended. The Rapid Response Surveys discussed in Chapter 3 are especially relevant and could be pursued as part of a more comprehensive crisis readiness approach. The creation of a mobile phone survey team along with the systematic collection of phone numbers of potential respondents, and the preparation of draft phone questionnaires that could be used, are small investments that would yield enormous benefits in terms of information availability during times of distress. Other measures to protect the integrity of the statistical system may also be considered, such as ensuring greater redundancy in the storage of data and reports, including by storing electronic copies off-site or in a cloud.

For fragile countries in which violence is likely, a business as usual approach is neither realistic nor desirable. The monetary as well as opportunity cost of collecting data, whether expressed in financial terms, risk, or use of scarce capacity is much higher in violent settings, and so it is critical to consider whether the envisaged benefits of producing the data are worth the price. Higher cost invariably means less data collection, so trade-offs need to be made. Complex household surveys, suited for non-violent situations, are rarely the instrument of choice in situations of violence. At times complex surveys can be simplifiedas is discussed in Chapter 9 using the rapid consumption methodology, but these approaches are technically challenging and for this reason only suited for low capacity environments if complemented with well-trained technical assistance.

When making choices on what to collect, it is important to realize that even in violent situations, many variables remain relatively unchanged over time. Collecting information on such slow-changing aspects should be less of a priority. Other aspects change rapidly in 
violent FCV environments. Insecurity and deteriorated infrastructure enhance volatility as markets become thinner. As a consequence, food insecurity is more easily at risk. Knowing perceptions, opinions and grievances of citizens is critical as they drive their expectations of the authorities and behavior, including support for local armed groups. So one should first seek answers to questions like: How do prices of key food items change? What is happening to wages, to food security? How are citizen perceptions evolving? How are displaced people cared for? Are interventions succeeding? These aspects should be monitored over time, before moving to more complex surveys.

This suggests that relative to non-violent settings, data collection programs in violent situations should be even more agile. The focus should be on updating information regularly and uncovering trends as opposed to collecting data that gives very precise information about levels. It is more important to know that food security is rapidly worsening than to know what exactly the percentage of food insecure people. This has implications for the way data collection systems are set up. Lighter surveys, or mobile phone surveys should be the standard tools for data collection in FCV settings. Lighter surveys have the advantage that they can be implemented more rapidly, require less capacity for training and analysis. And once call centers have been set up, and phone numbers of different (potential) target groups have been collected, they can be used repeatedly.

With this book we hope to have pointed practitioners to relevant alternatives which can help meet critical data needs, even in the most difficult circumstances. Mobile phone surveys, discussed in Chapters 2-5 give a flavor of the possibilities. When mobile phone surveys are not an option and face-to-face interviews need to be conducted, alternatives can be found by relying on resident enumerators (discussed in Chapter 5), or by designing light data collection instruments like the commune census discussed in Chapter 6. When topics are narrower, for instance whether interventions are succeeding, then iterative beneficiary monitoring (IBM) (Chapter 13) offers an approach that can be followed. When sensitive questions need to be asked or when one is afraid responses might be biased, Chapters 10 and 11 offer pointers. 
By sharing these innovations, we hope that many more people can benefit from them, joining us in our attempts to reduce data deprivation and, more importantly, extreme poverty. This book is prepared with practitioners in mind, and when necessary, we focused on showcasing examples rather than elaborating technical details of the approaches. We realize that the proposed approaches vary in complexity, time intensity and cost. Some require a high level of technical expertise at the design stage, others are expensive or difficult to implement. Table 1 may serve as a guide on the kind of expertise that is needed to apply the different approaches discussed in this book.

We welcome feedback and enquiries and are happy to explain in greater depth the methods used and the approaches taken. Contact details for the authors can be found in the section on contributors.

Table 1 Resource requirements to implementing methods described in various chapters

$\begin{array}{cl}\text { Chapter } & \text { Chapter topic } \\ 2 & \text { Mobile phone surveys } \\ 3 & \text { Rapid reponse survey } \\ 4 & \text { Tracking displaced people } \\ 5 & \text { Locally recruited enumerators } \\ 6 & \text { Local development index } \\ 7 & \text { Geo spatial sampling } \\ 8 & \text { Sampling displaced populations } \\ 9 & \text { Rapid consumption surveys } \\ 10 & \text { Studying sensitive topics } \\ 11 & \text { Accurate responses } \\ 12 & \text { Video testimonials } \\ 13 & \text { Iterative beneficiary monitoring }\end{array}$

\begin{tabular}{ccccc}
$\begin{array}{c}\text { Design } \\
\text { complexity }\end{array}$ & $\begin{array}{c}\text { Implementation } \\
\text { capacity }\end{array}$ & $\begin{array}{c}\text { Analytical } \\
\text { complexity }\end{array}$ & $\begin{array}{c}\text { Cost } \\
\text { Time needed }\end{array}$ \\
\hline 2 & 1 & 2 & 2 & 1 \\
3 & 2 & 2 & 2 & 1 \\
3 & 2 & 2 & 2 & 2 \\
3 & 3 & 2 & 2 & 2 \\
\hline 2 & 2 & 1 & 1 & 1 \\
\hline 4 & 3 & 3 & 4 & 3 \\
\hline 3 & 3 & 3 & 2 & 2 \\
\hline 4 & 4 & 4 & 4 & 4 \\
\hline 3 & 2 & 3 & 1 & 1 \\
\hline 2 & 1 & 3 & 1 & 2 \\
\hline 3 & 2 & 1 & 1 & 1 \\
\hline 1 & 1 & 1 & 1 & 1 \\
\hline
\end{tabular}


The opinions expressed in this chapter are those of the author(s) and do not necessarily reflect the views of the International Bank for Reconstruction and Development/The World Bank, its Board of Directors, or the countries they represent.

Open Access This chapter is licensed under the terms of the Creative Commons Attribution 3.0 IGO license (https://creativecommons.org/ licenses/by/3.0/igo/), which permits use, sharing, adaptation, distribution and reproduction in any medium or format, as long as you give appropriate credit to the International Bank for Reconstruction and Development/The World Bank, provide a link to the Creative Commons license and indicate if changes were made.

Any dispute related to the use of the works of the International Bank for Reconstruction and Development/The World Bank that cannot be settled amicably shall be submitted to arbitration pursuant to the UNCITRAL rules. The use of the International Bank for Reconstruction and Development/The World Bank's name for any purpose other than for attribution, and the use of the International Bank for Reconstruction and Development/The World Bank's logo, shall be subject to a separate written license agreement between the International Bank for Reconstruction and Development/The World Bank and the user and is not authorized as part of this CC-IGO license. Note that the link provided above includes additional terms and conditions of the license.

The images or other third party material in this chapter are included in the chapter's Creative Commons license, unless indicated otherwise in a credit line to the material. If material is not included in the chapter's Creative Commons license and your intended use is not permitted by statutory regulation or exceeds the permitted use, you will need to obtain permission directly from the copyright holder.

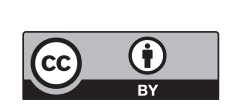

